Supplement of Hydrol. Earth Syst. Sci., 25, 867-883, 2021

https://doi.org/10.5194/hess-25-867-2021-supplement

(c) Author(s) 2021. This work is distributed under

the Creative Commons Attribution 4.0 License.

(c) (1)
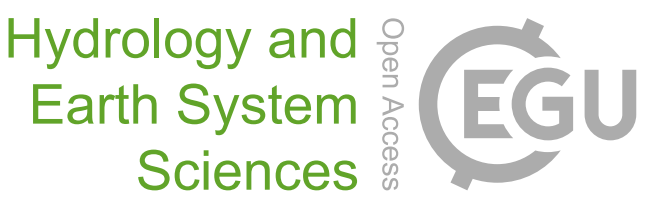

Supplement of

\title{
Intensive landscape-scale remediation improves water quality of an alluvial gully located in a Great Barrier Reef catchment
}

Nicholas J. C. Doriean et al.

Correspondence to: Andrew P. Brooks (andrew.brooks@griffith.edu.au)

The copyright of individual parts of the supplement might differ from the CC BY 4.0 License. 


\section{S1}

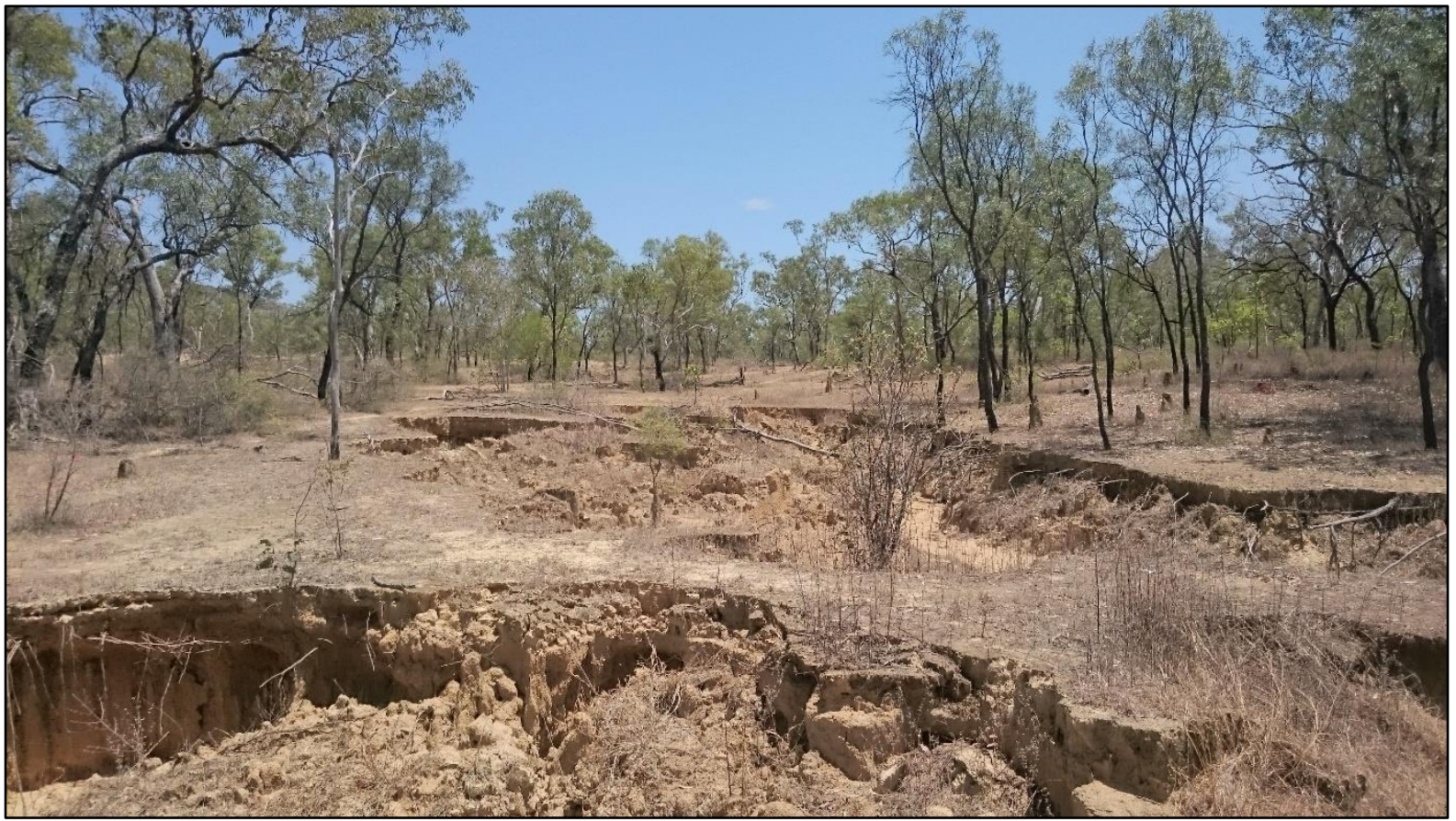

Figure S1A. A lobe of the remediated gully, prior to remediation.

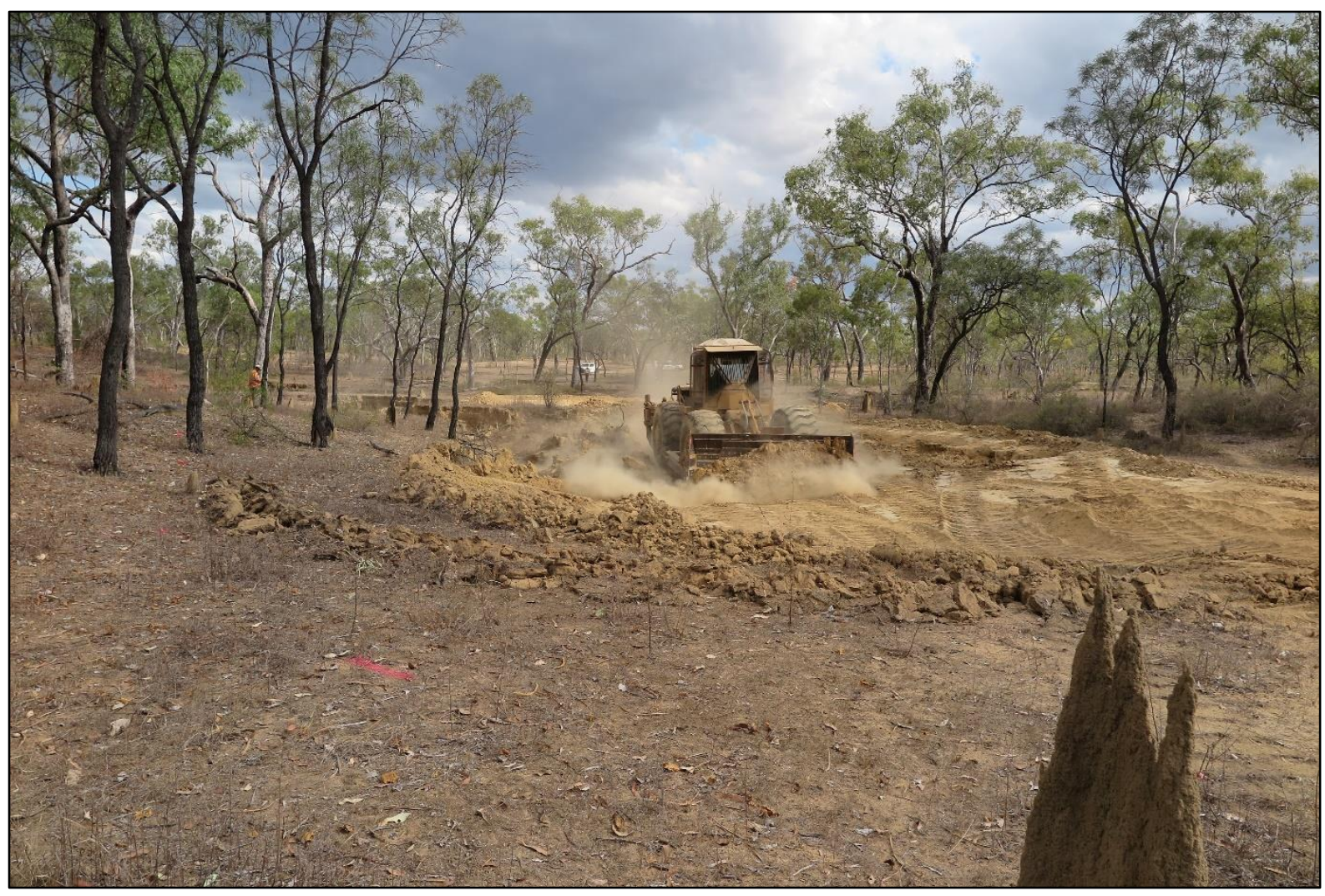

Figure S1B. Reshaping the remediated gully. 
S1

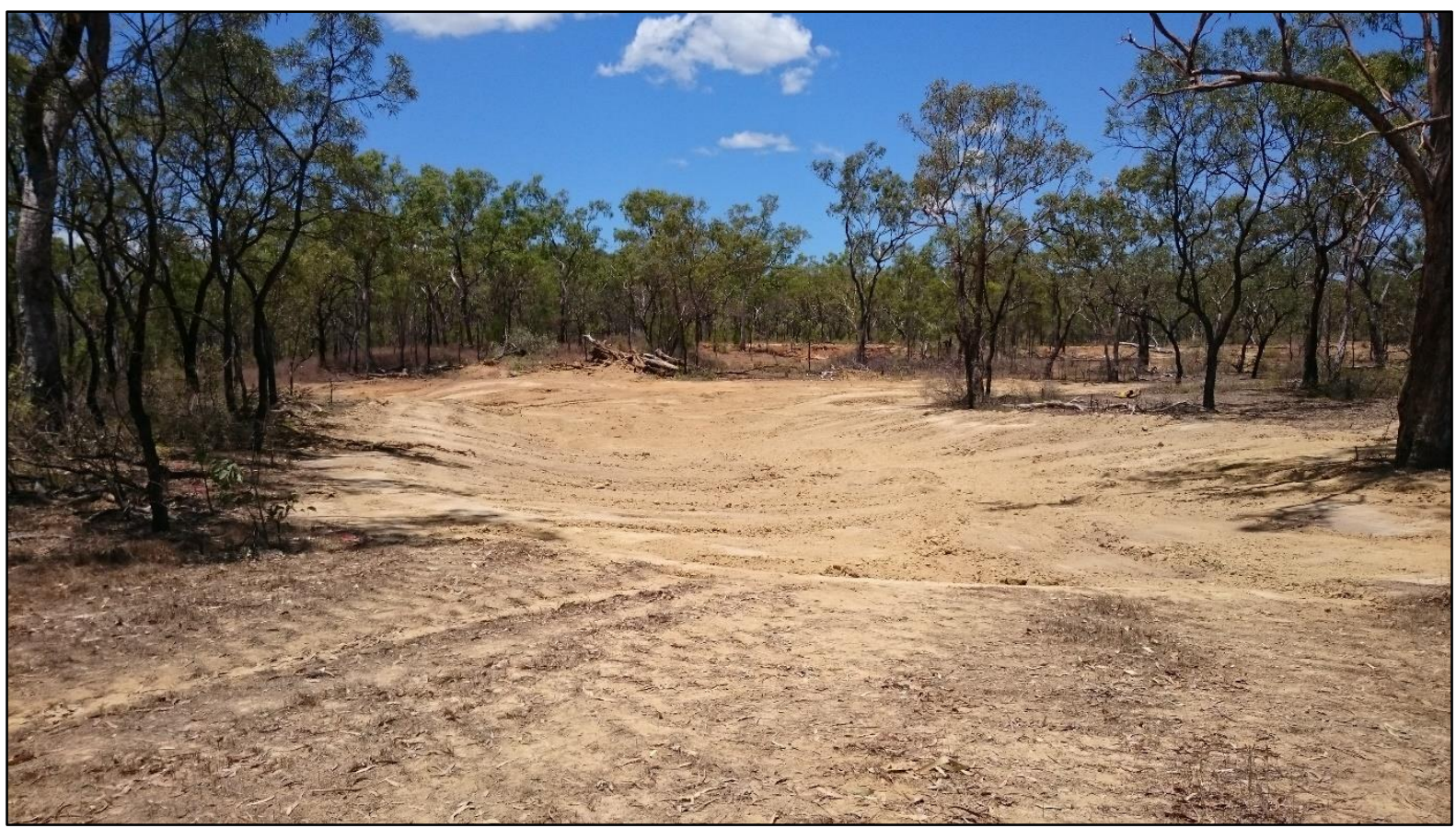

Figure S1C. Finished reshaping of remediated gully.

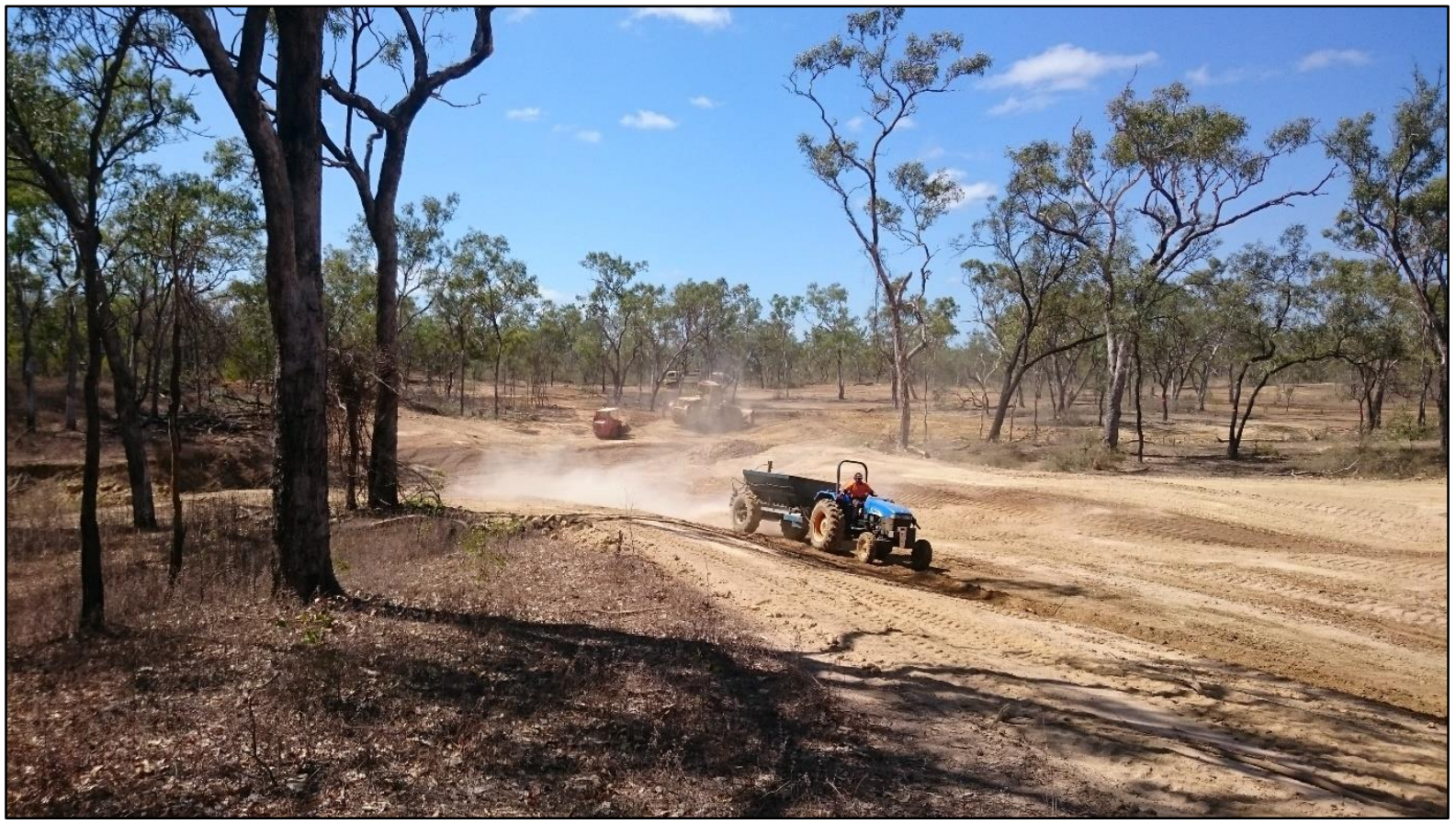

Figure S1D. Spreading gypsum over remediated gully. 
S1

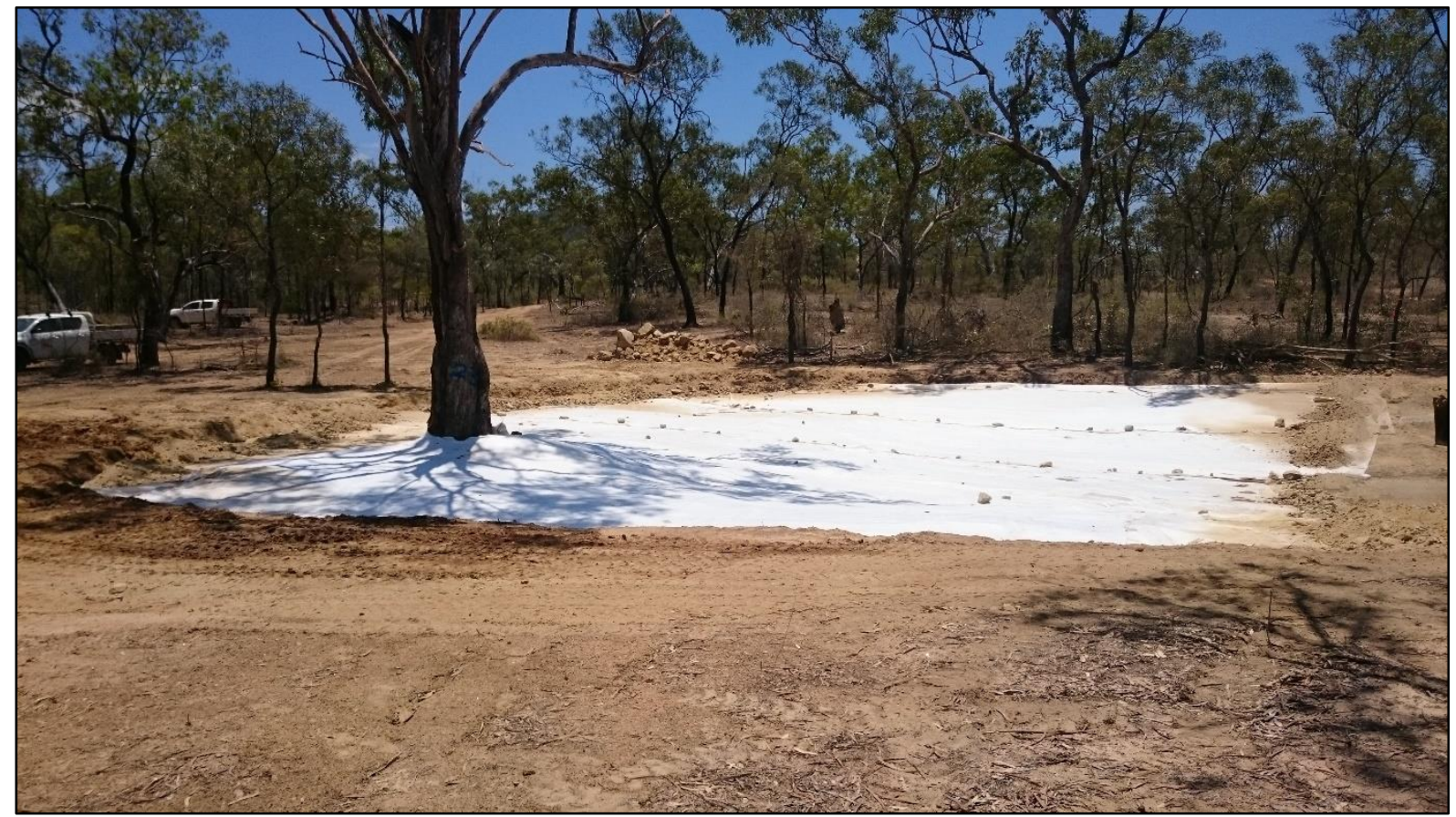

Figure S1E. Geotextile fabric laid over former gully head scarp

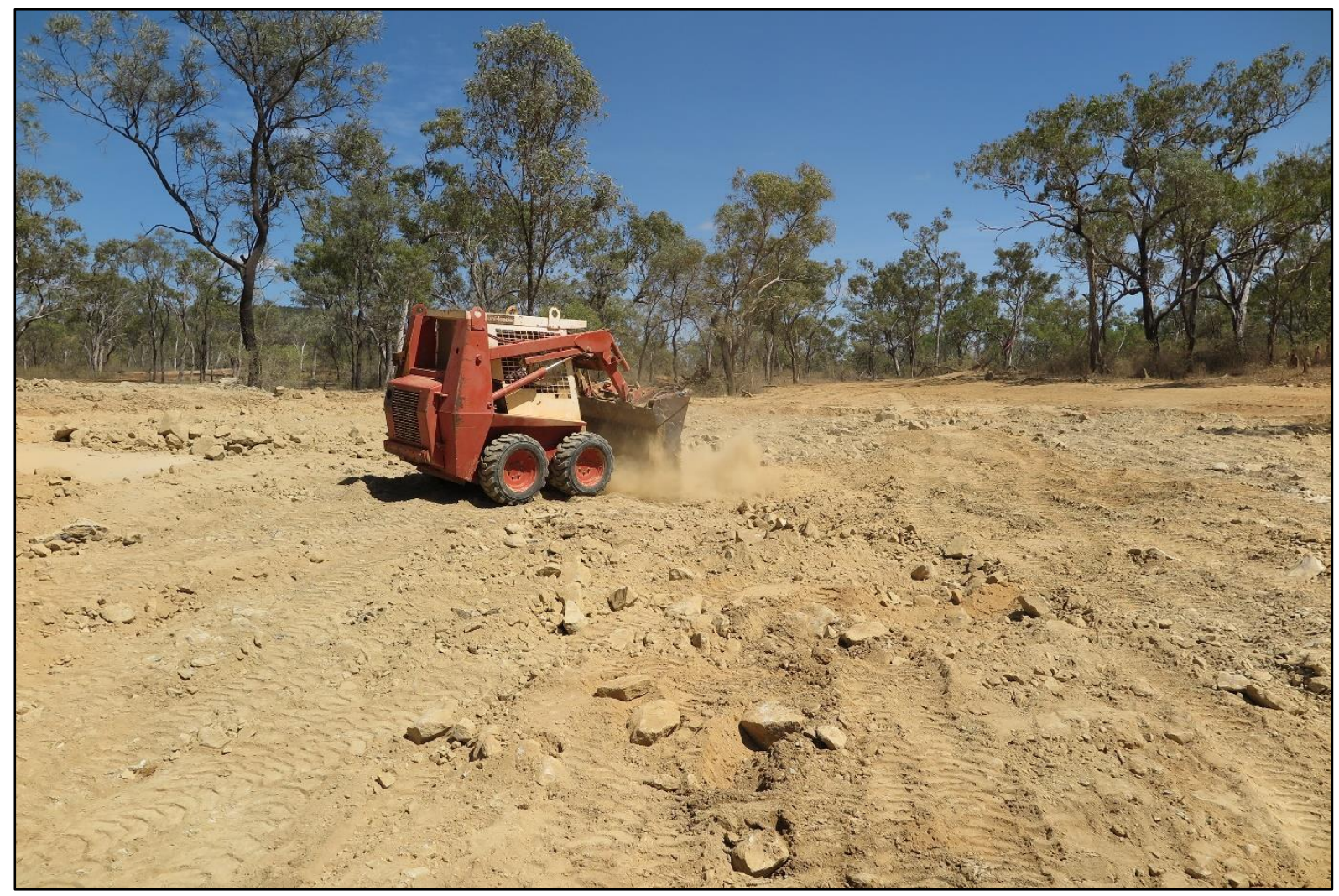

Figure S1F. Rock capping remediated gully. 
S1

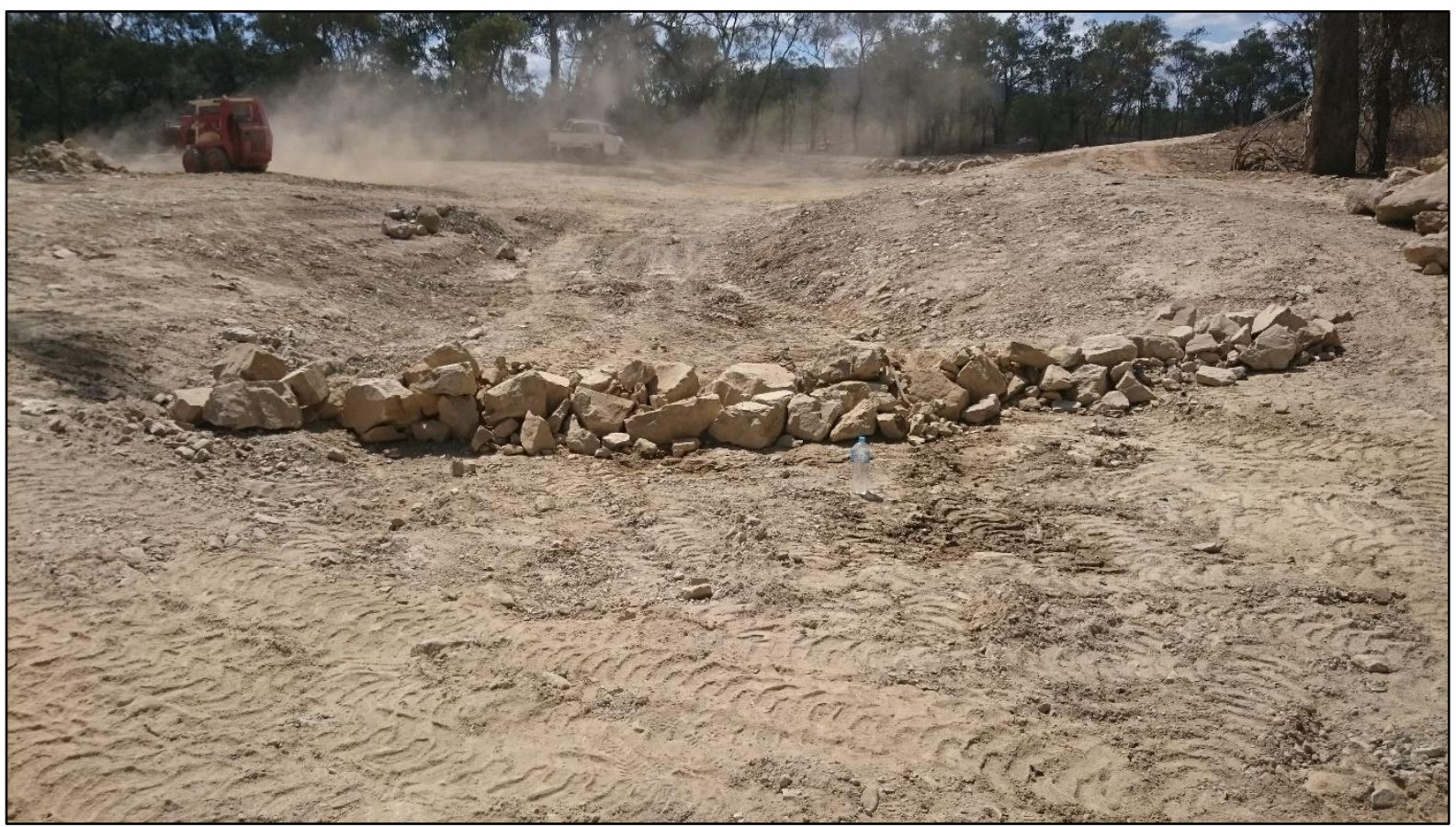

Figure S1G. Remediated gully completed with check dams 2016.

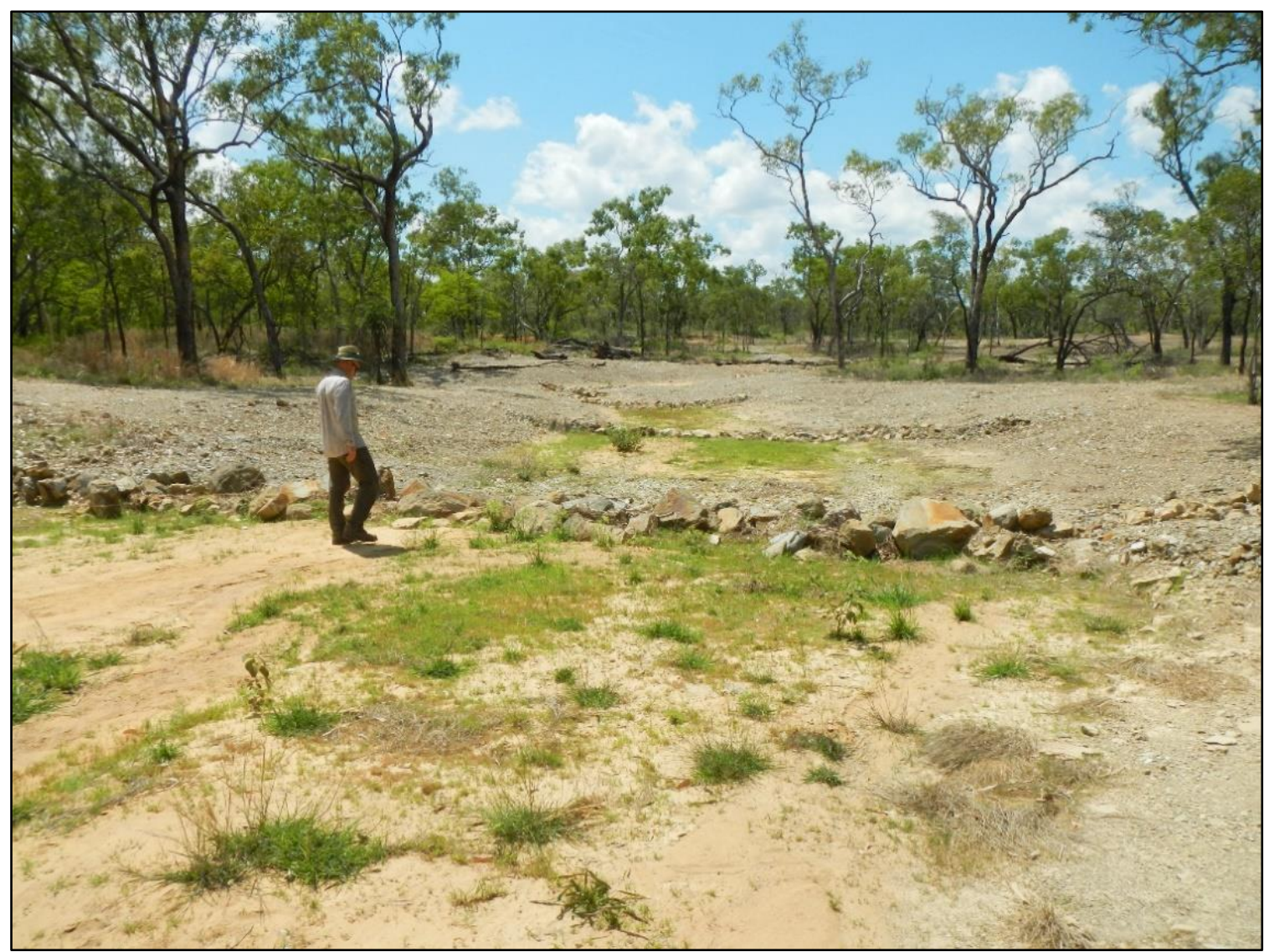

Figure S1H. Remediated gully 2017 


\section{S1}

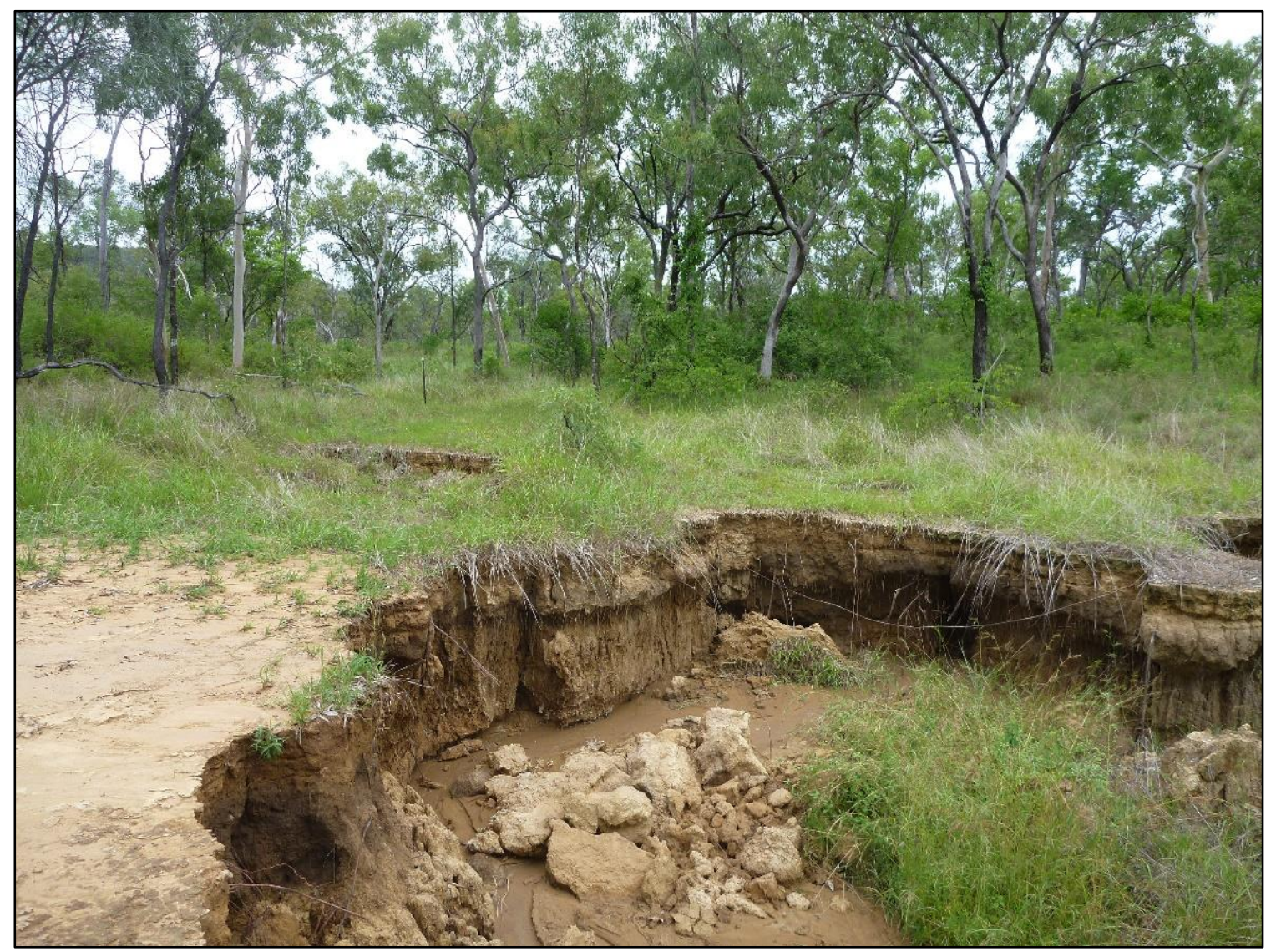

Figure S1I. Control Gully 2018. 


\section{S2}

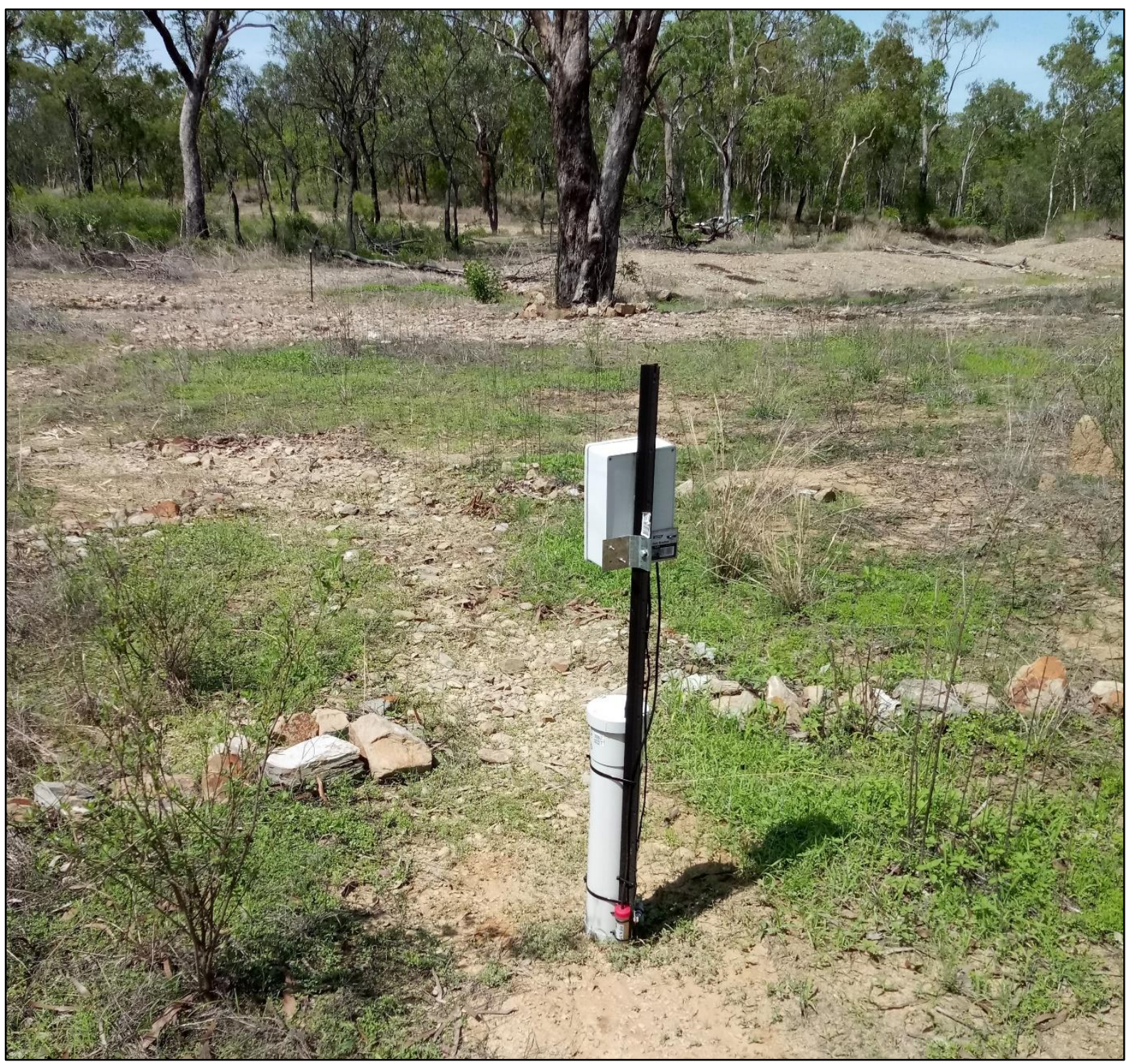

Figure S2 PASS sampler located in catchment drainage channel, upstream of the remediated gully. 

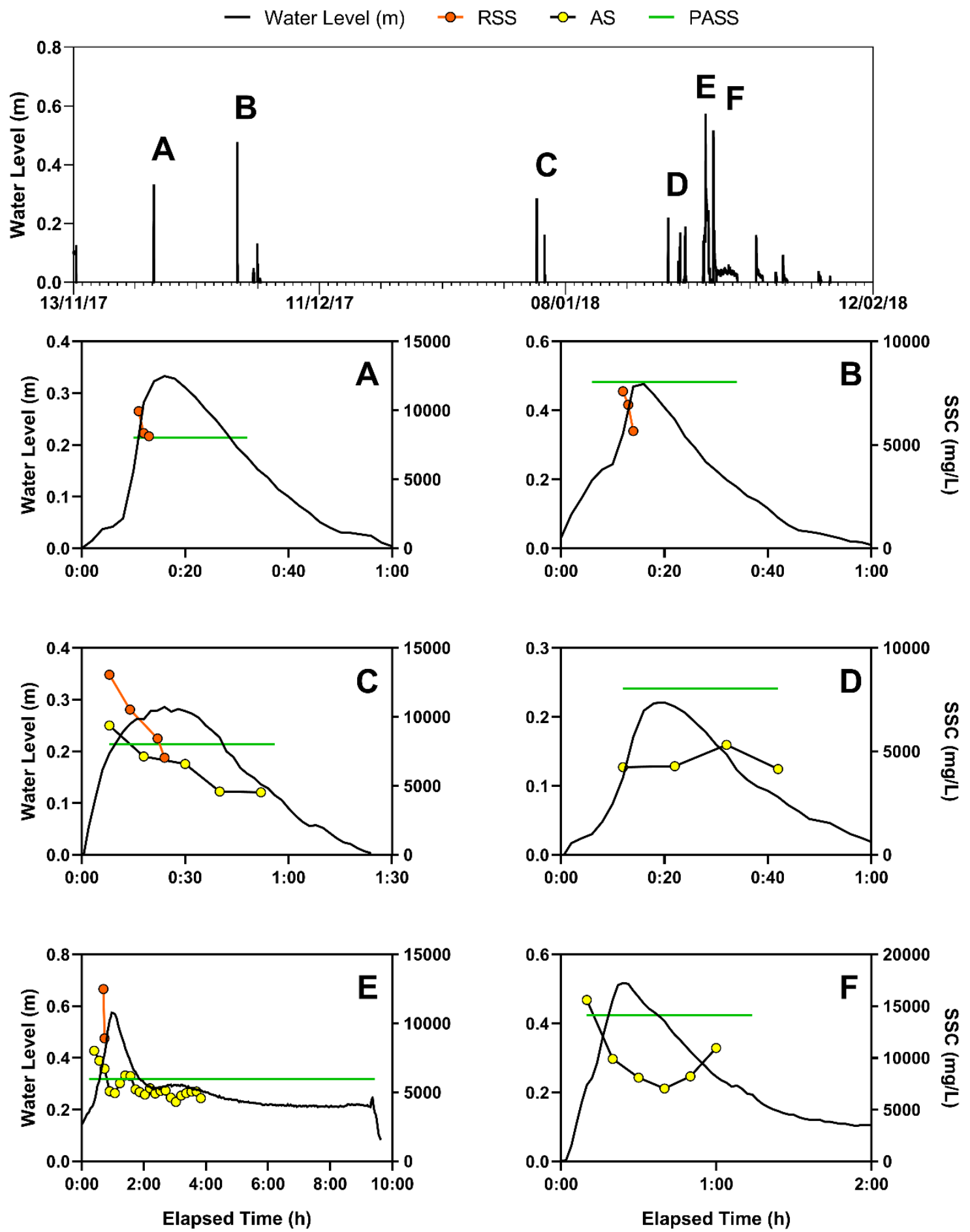

Figure S3A Timeline of flow events that occurred in the control gully during the 2017/2018 wet season. The top panel shows the water level for the heights for each flow event over the wet season. The individual panels show the water level (black line) and sample suspended sediment concentration data (orange $=\mathbf{R S}$ sampler, green $=$ PASS sampler, yellow $=$ autosampler, and red $=$ flow proportional manual sampling). 
- Water Level (m) $\quad$ - RSS $\multimap$ AS - PASS
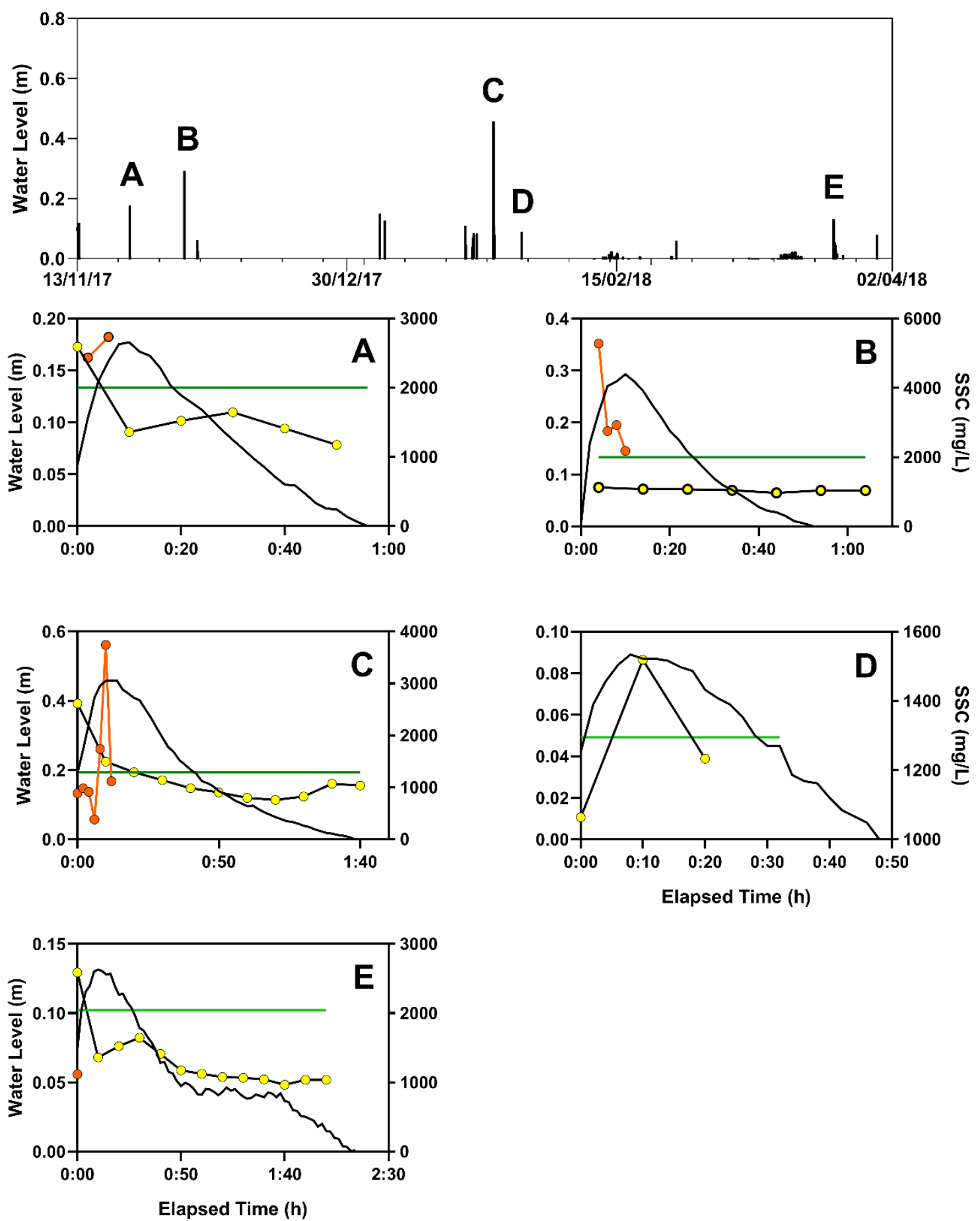

Figure S3B Timeline of flow events that occurred in the remediated gully during the 2017/2018 wet season. The top panel shows the water level for the heights for each flow event over the wet season. The individual panels show the water level (black line) and sample suspended sediment concentration data (orange $=$ RS sampler, green $=$ PASS sampler, yellow = autosampler, and red = flow proportional manual sampling). 

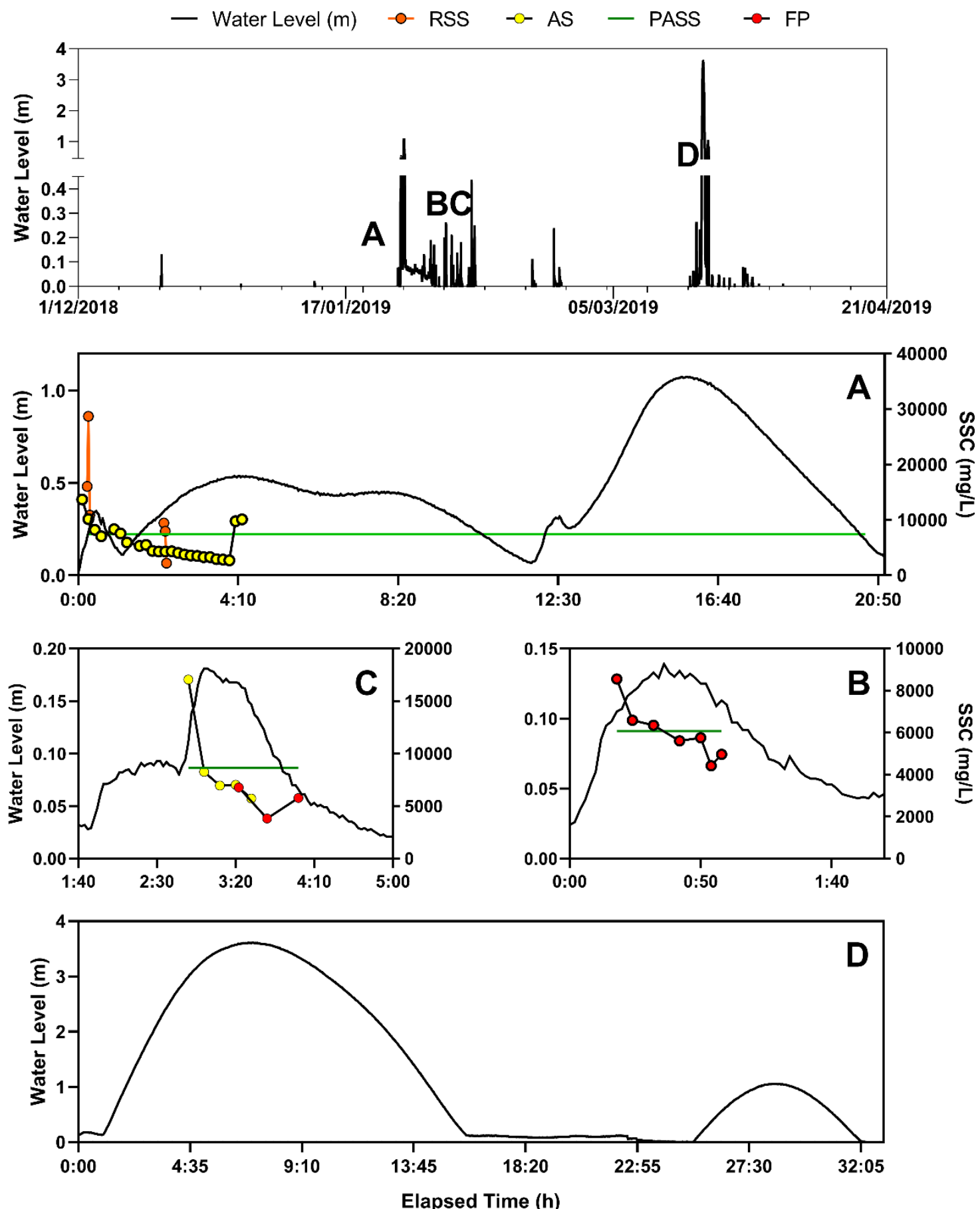

Figure S3C Timeline of flow events that occurred in the Control gully during the 2018/2019 wet season. The top panel shows the water level for the heights for each flow event over the wet season. The individual panels show the water level (black line) and sample suspended sediment concentration data (orange $=$ RS sampler, green $=$ PASS sampler, yellow = autosampler, and red = flow proportional manual sampling). 
- Water Level (m) $\quad$ -
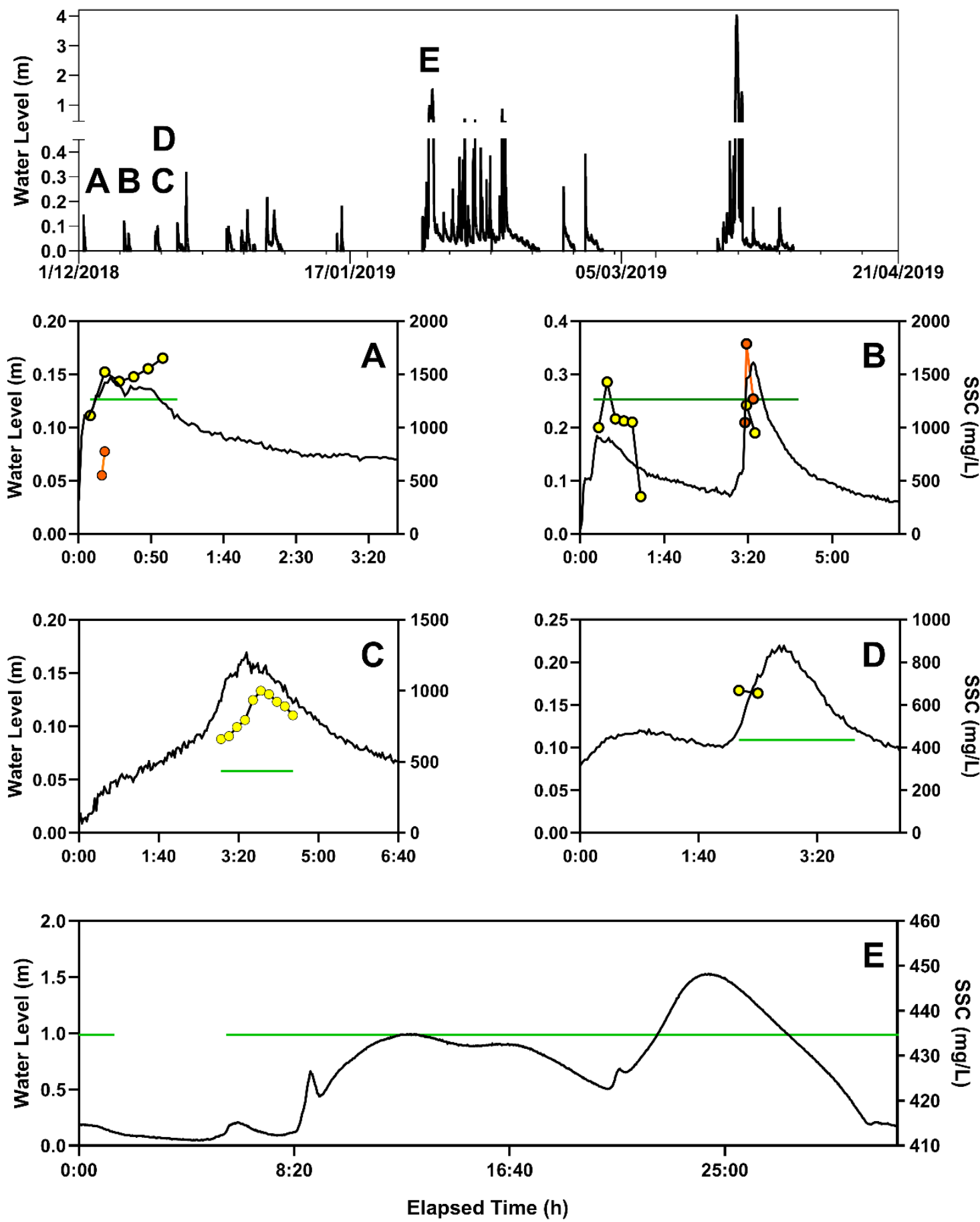

Figure S3D Timeline of flow events that occurred in the Remediated gully during the first half of 2018/2019 wet season (i.e., up to January 2019). The top panel shows the water level for the heights for each flow event over the wet season. The individual panels show the water level (black line) and sample suspended sediment concentration data (orange $=$ RS sampler, green $=$ PASS sampler, yellow $=$ autosampler, and red $=$ flow proportional manual sampling). 
- Water Level (m) — PASS $\multimap$ FP
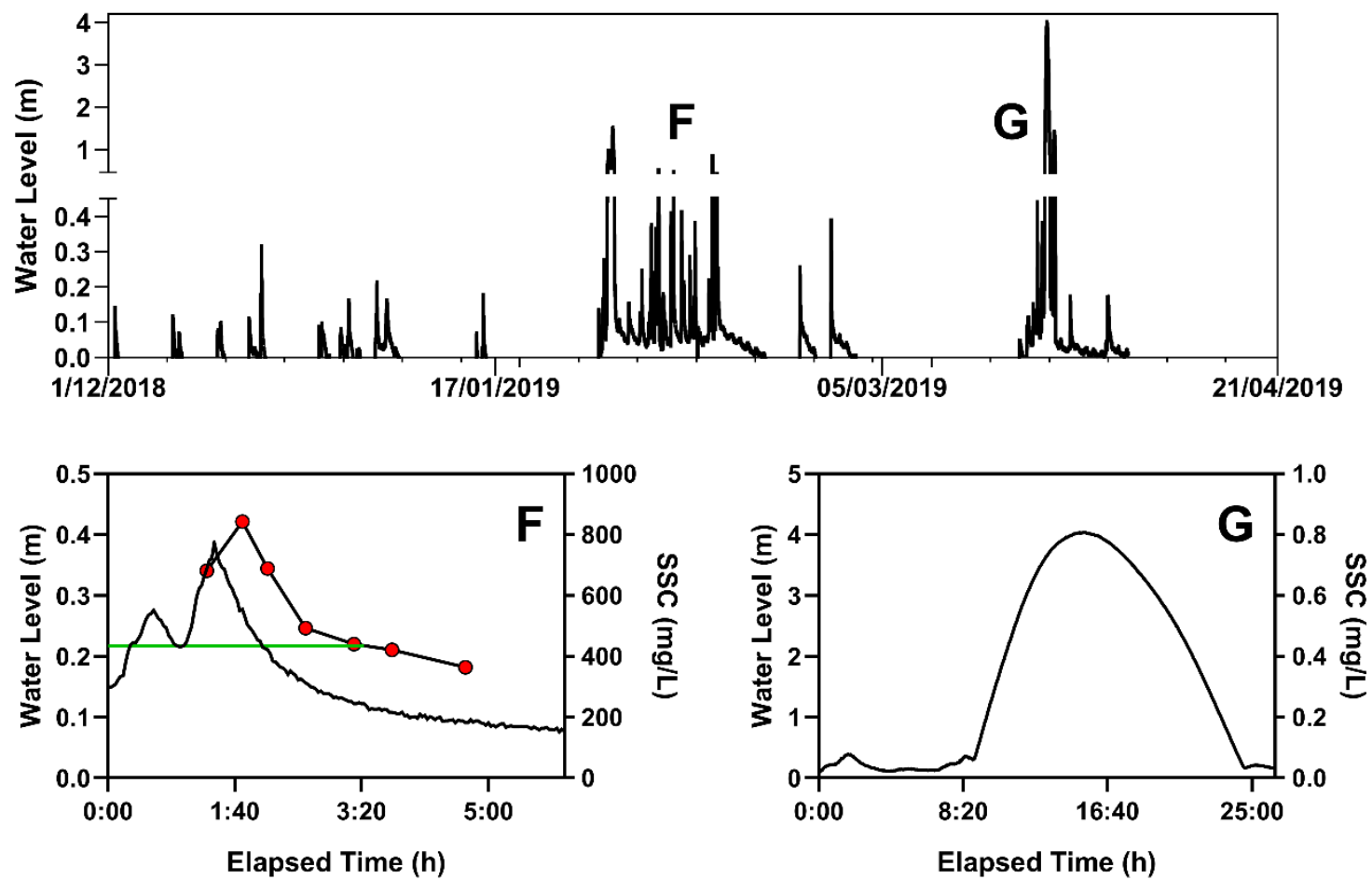

Figure S3D Timeline of flow events that occurred in the Remediated gully during the second half of 2018/2019 wet season (i.e., February to April 2019). The top panel shows the water level for the heights for each flow event over the wet season. The individual panels show the water level (black line) and sample suspended sediment concentration data (orange $=$ RS sampler, green $=$ PASS sampler, yellow $=$ autosampler, and red $=$ flow proportional manual sampling). 
S4

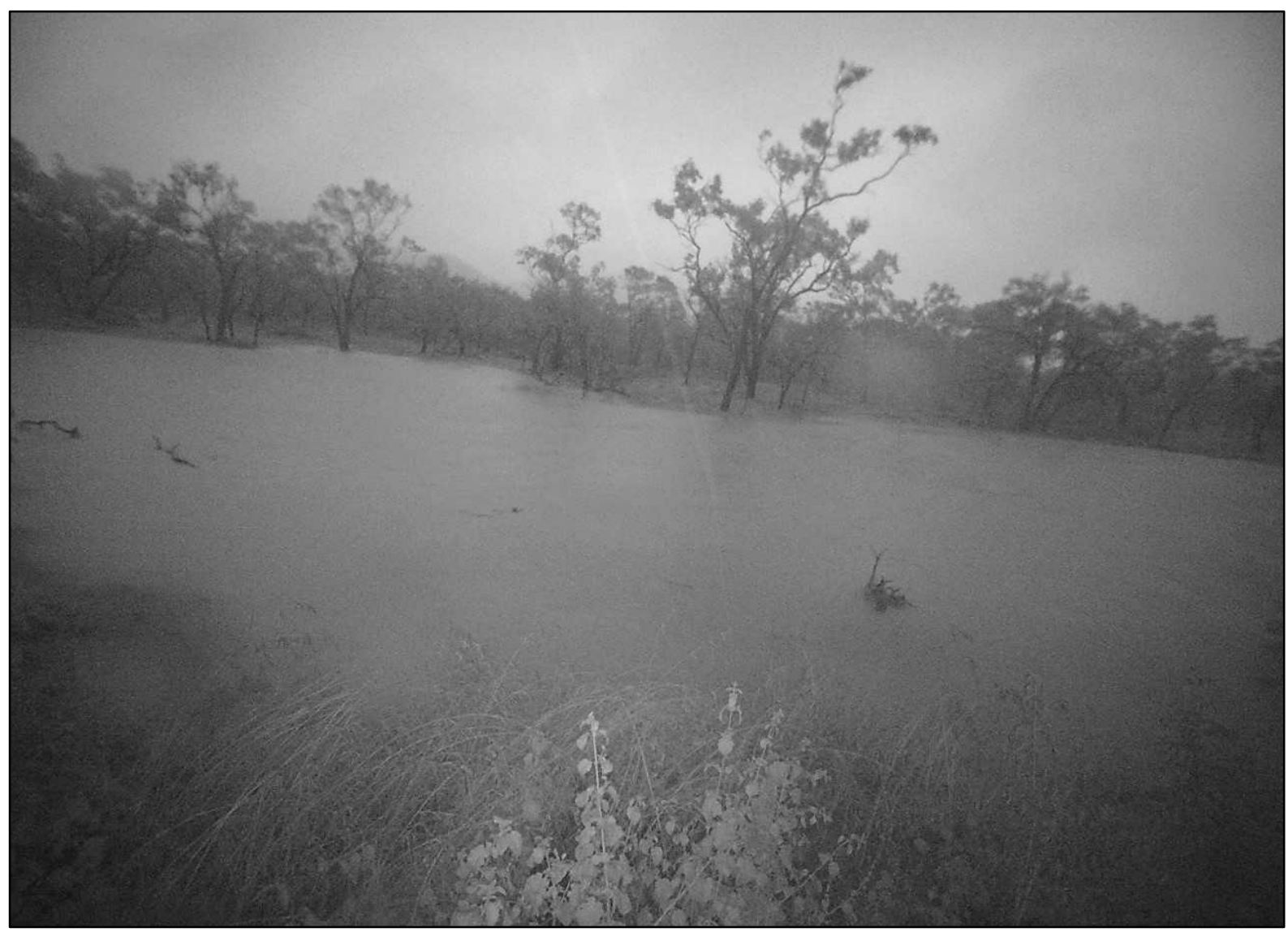

Figure S4A. Infrared image of remediated gully flooded during January 2019 backwater event. 


\section{S4}

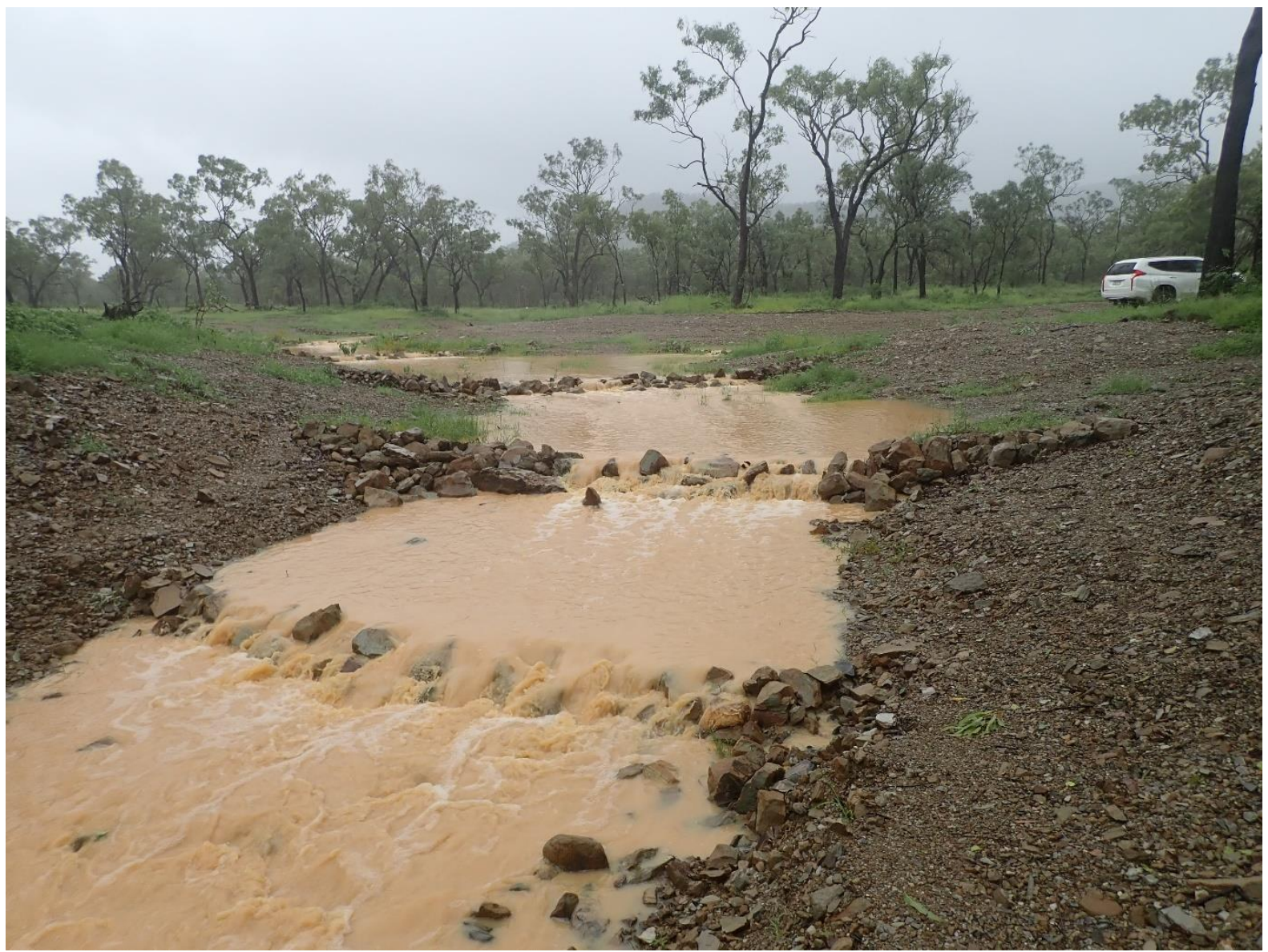

Figure S4B Remediated gully during small flow event on 6 February 2019. 


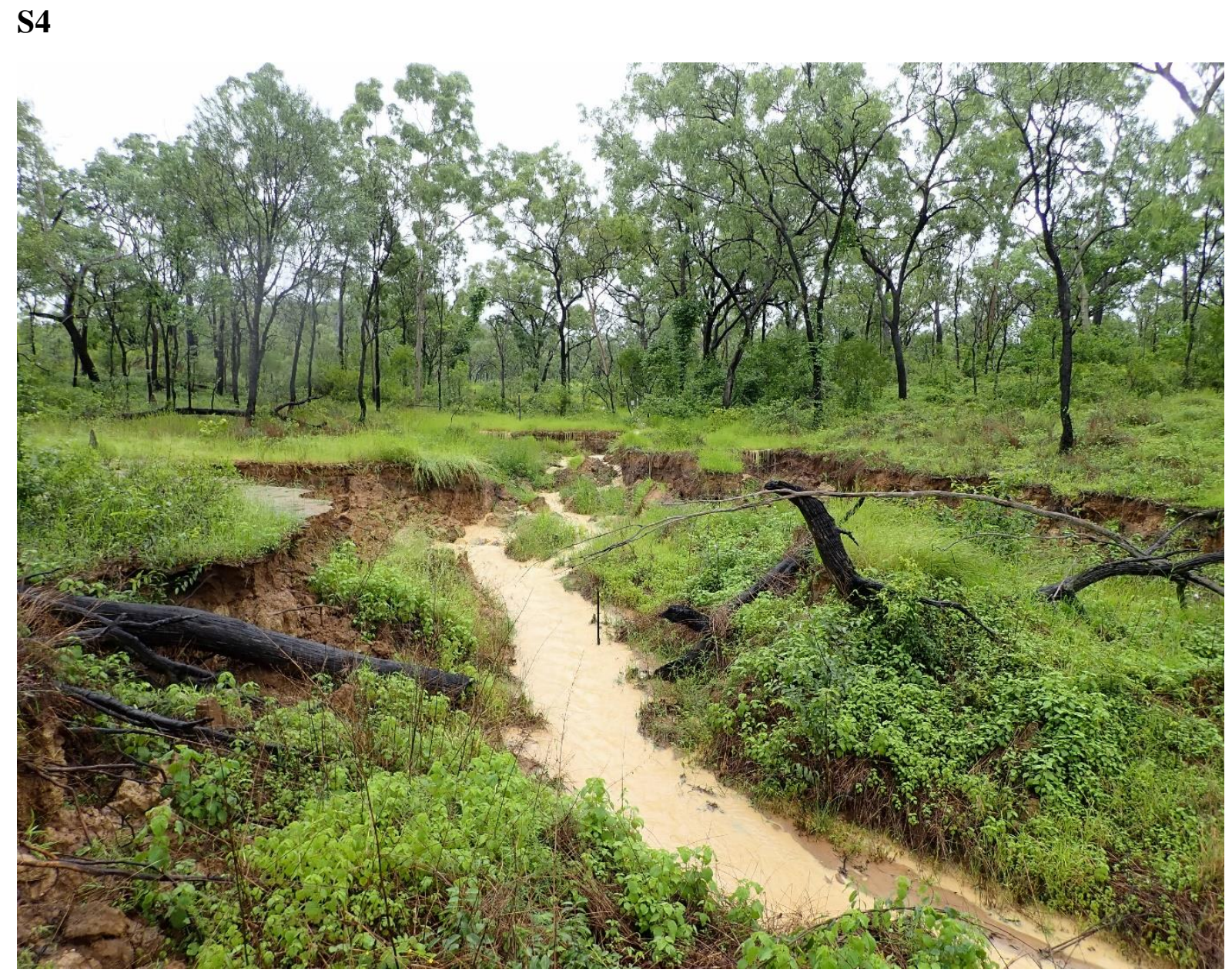

Figure S4C: Control gully during small flow event on 6 February 2019 


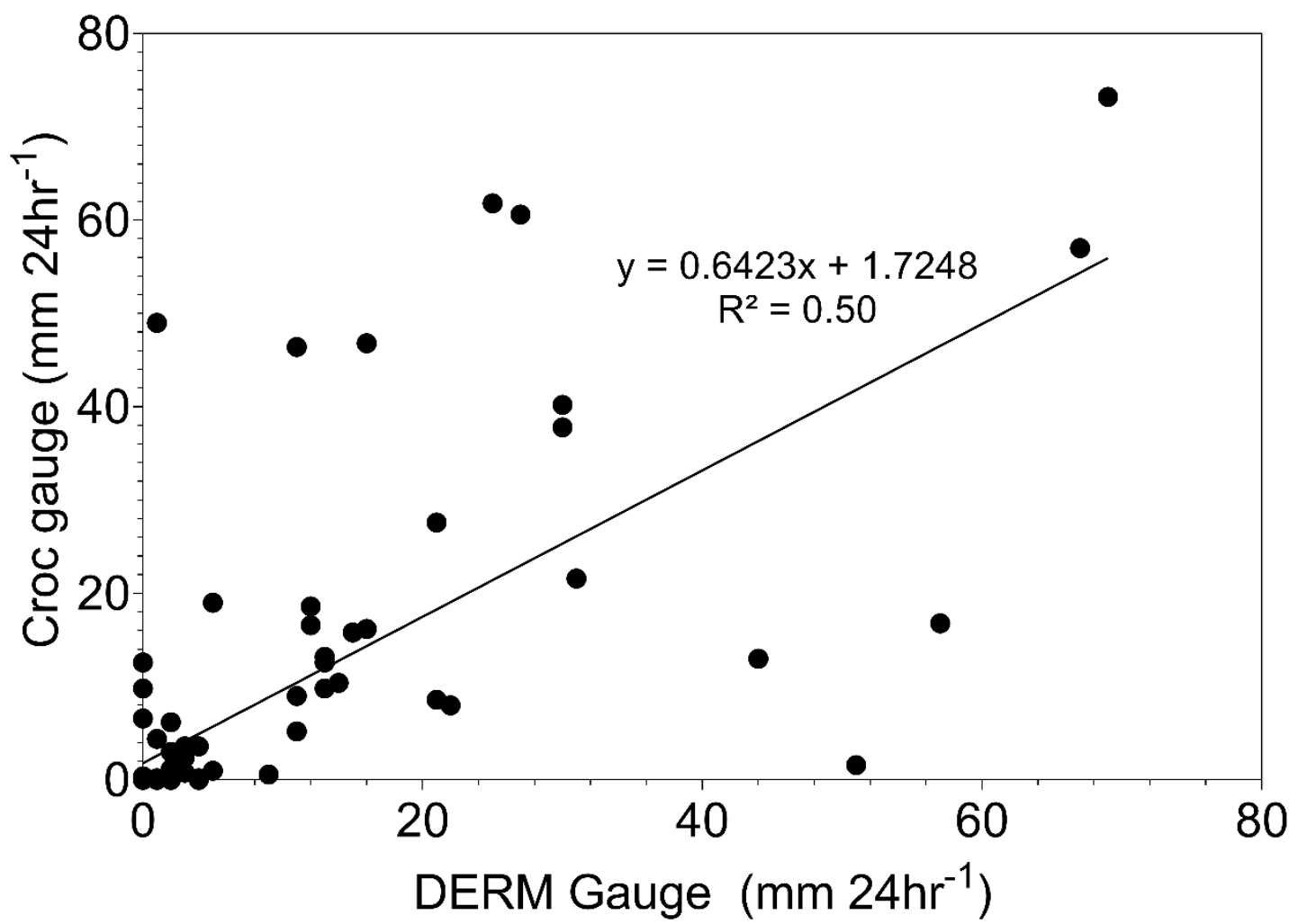

Figure S5. Linear correlation between daily total rainfall measured using raingauges located at the study site and the Coal Seam Creek Stream Gauge on the Laura River. 
S6

Table S6. Density of gully sediment

\begin{tabular}{ccc}
\hline Sample Number & size class $(\boldsymbol{\mu m})$ & Density $(\mathbf{g} / \mathbf{m L})$ \\
\hline 1 & $<63$ & 2.30 \\
\hline 2 & $<63$ & 2.30 \\
\hline 3 & $<63$ & 2.26 \\
\hline 4 & $<63$ & 2.28 \\
\hline 5 & $63-2000$ & 2.43 \\
\hline 6 & $63-2000$ & 2.44 \\
\hline 7 & $63-2000$ & 2.40 \\
\hline Average & & 2.34 \\
\hline Standard deviation & & 0.08 \\
\hline RSD & & $3 \%$ \\
\hline
\end{tabular}

Please note, in-order to have enough sediment mass, density testing was conducted on gully sediment from the control gully and assumed to be comparable to remediated gully sediment, based on soil chemistry and PSD. 

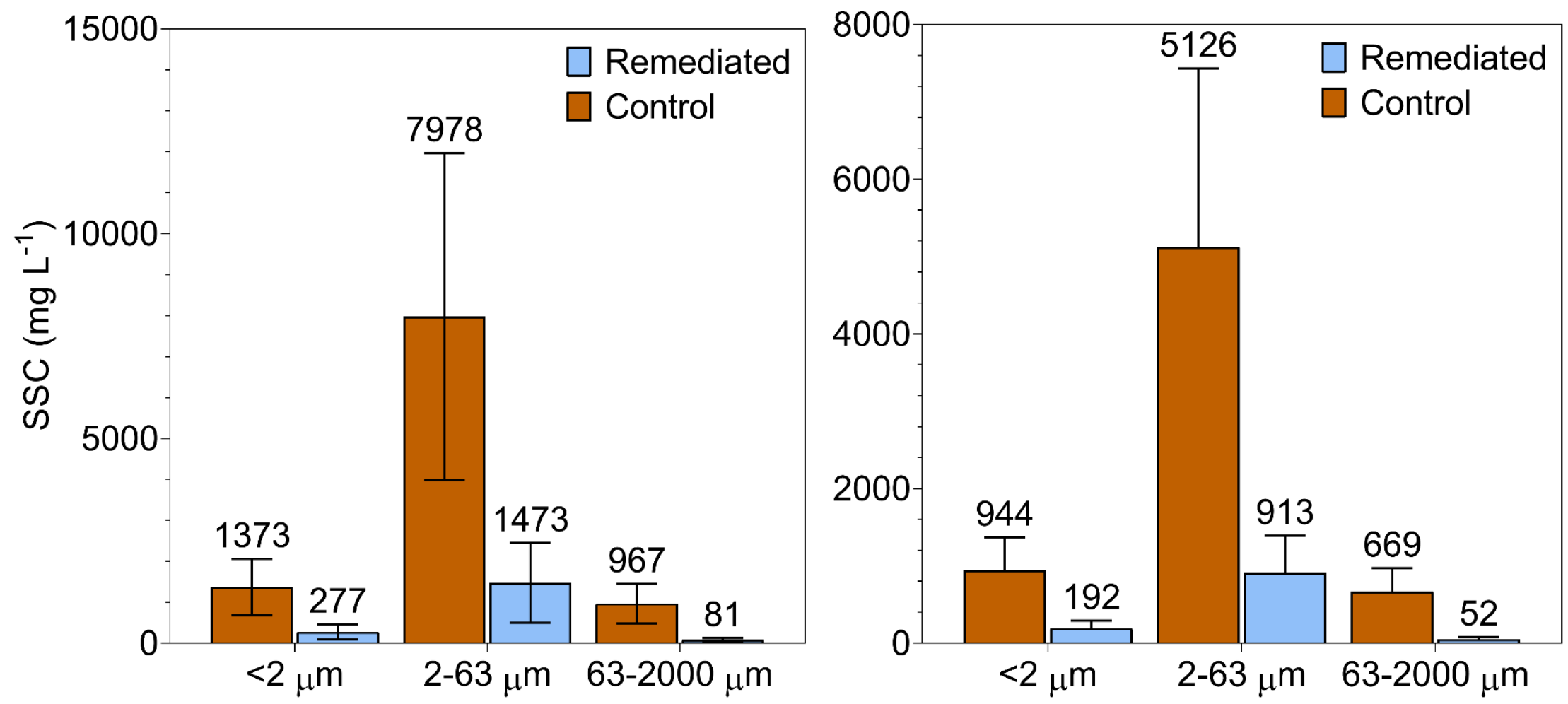

Figure S7 SSC by PSD for samples collected using autosamplers (left) and RS samplers (right) from the control (brown) and remediated (blue) gullies during the 2017/2018 and 2018/2019 wet seasons. 
Table S8. Statistical comparison of control and remediated gully soil PSD measurements.

\begin{tabular}{|c|c|c|c|c|c|c|c|c|}
\hline Soil size $(\mu \mathrm{m})$ & Significant? & $p$ value & Mean of Control & Mean of Remediated & Difference & SE of difference & tratio & $d f$ \\
\hline$>2000$ & No & 0.219477 & 2.25 & 0.9133 & 1.34 & 1.05 & 1.28 & 17 \\
\hline $2000-50$ & No & 0.617292 & 47.75 & 43.23 & 4.52 & 8.89 & 0.51 & 17 \\
\hline $50-20$ & No & 0.724715 & 61.25 & 57.97 & 3.28 & 9.17 & 0.36 & 17 \\
\hline $2-20$ & No & 0.699885 & 19.25 & 21.58 & -2.33 & 5.94 & 0.39 & 17 \\
\hline$<2$ & No & 0.830985 & 19.25 & 20.43 & -1.18 & 5.46 & 0.22 & 17 \\
\hline
\end{tabular}


S9

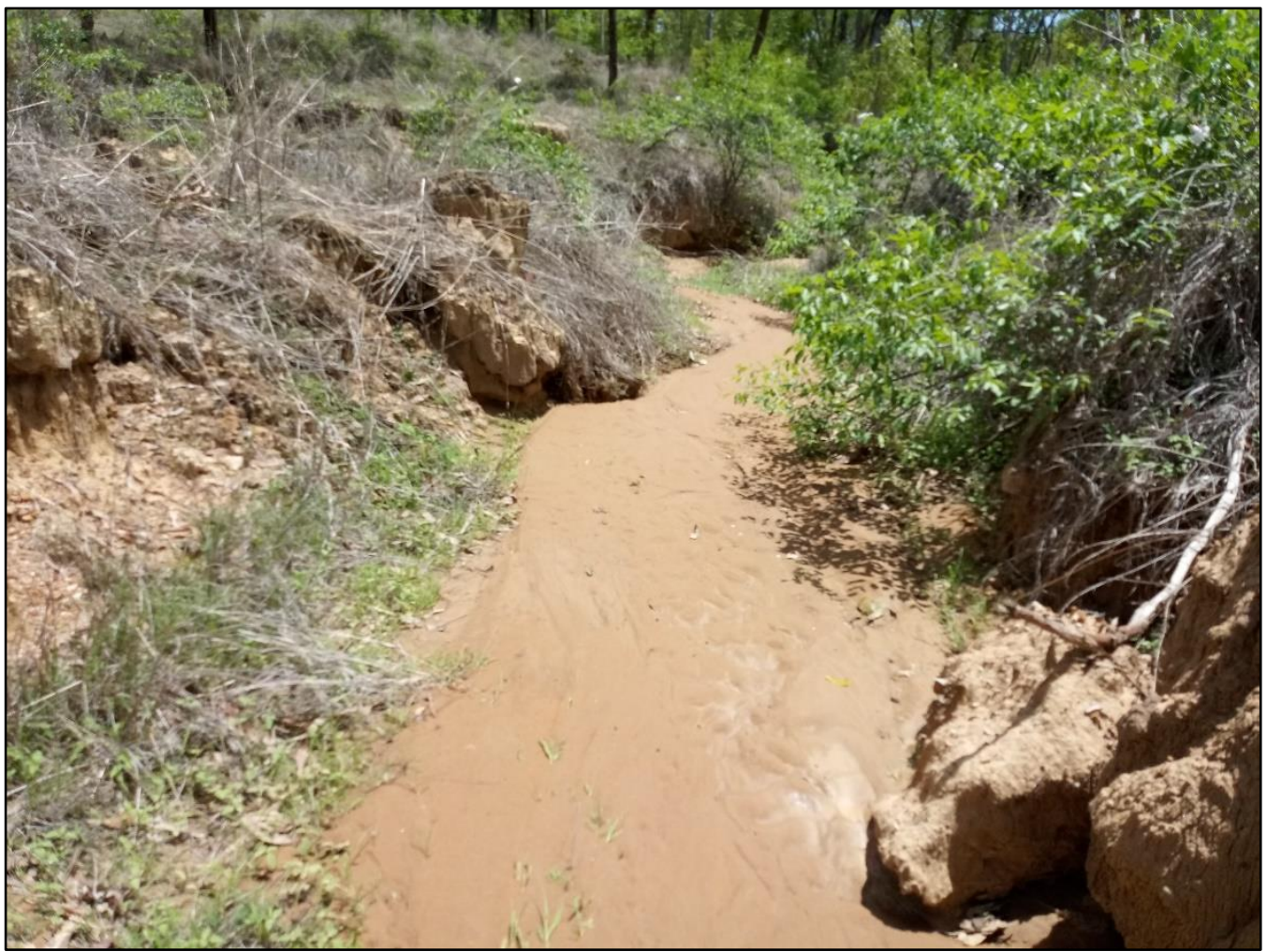

Figure S9A. Looking down stream at the outlet channel from control gully head. Photo taken in on 16/02/2018. Note large deposit of sand making up channel bed. 


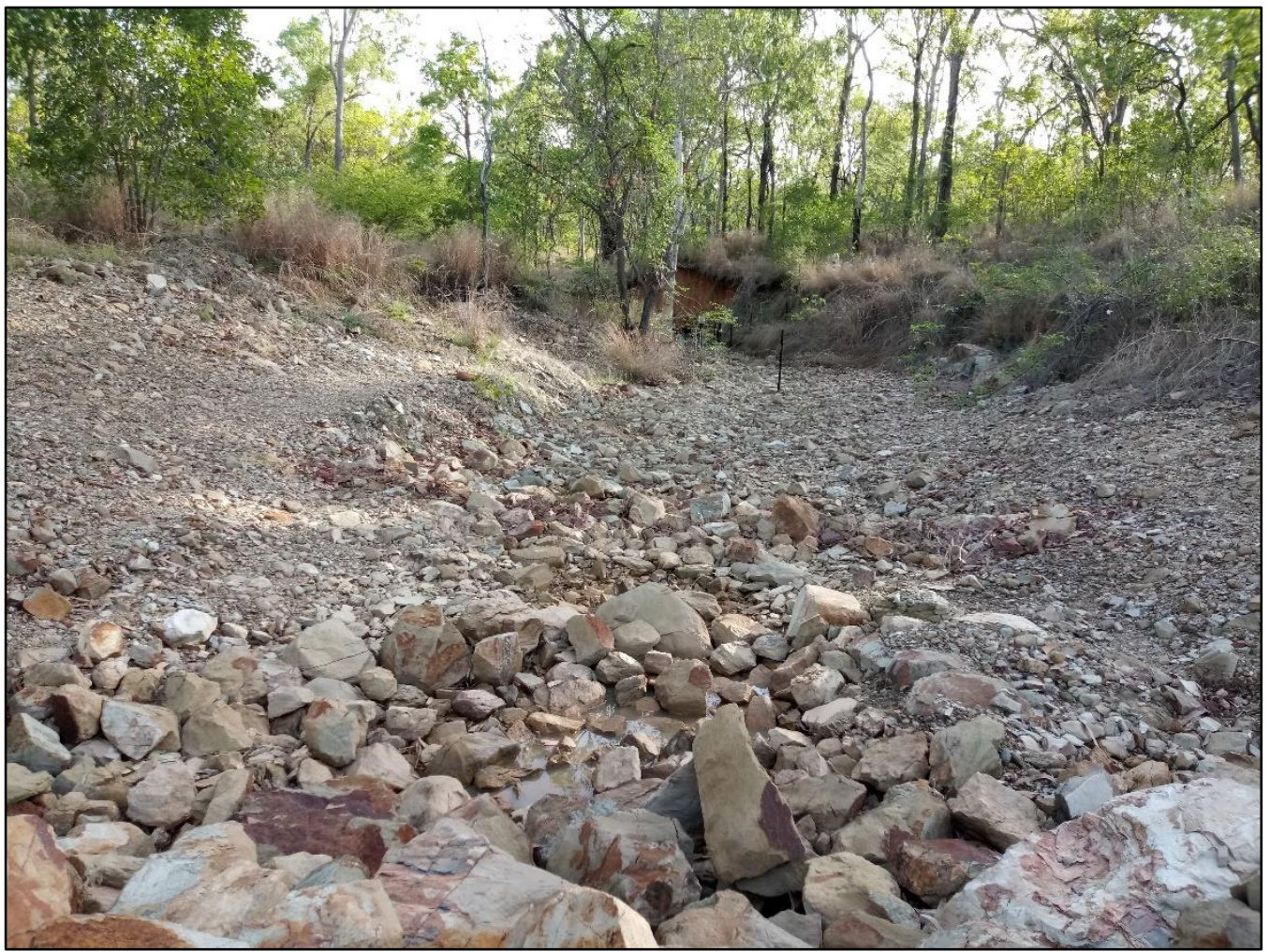

Figure S9B. Looking downstream from at remediated gully head outlet channel. Photo taken in on 16/02/2018. Note the lack of sediment in the channel bed.

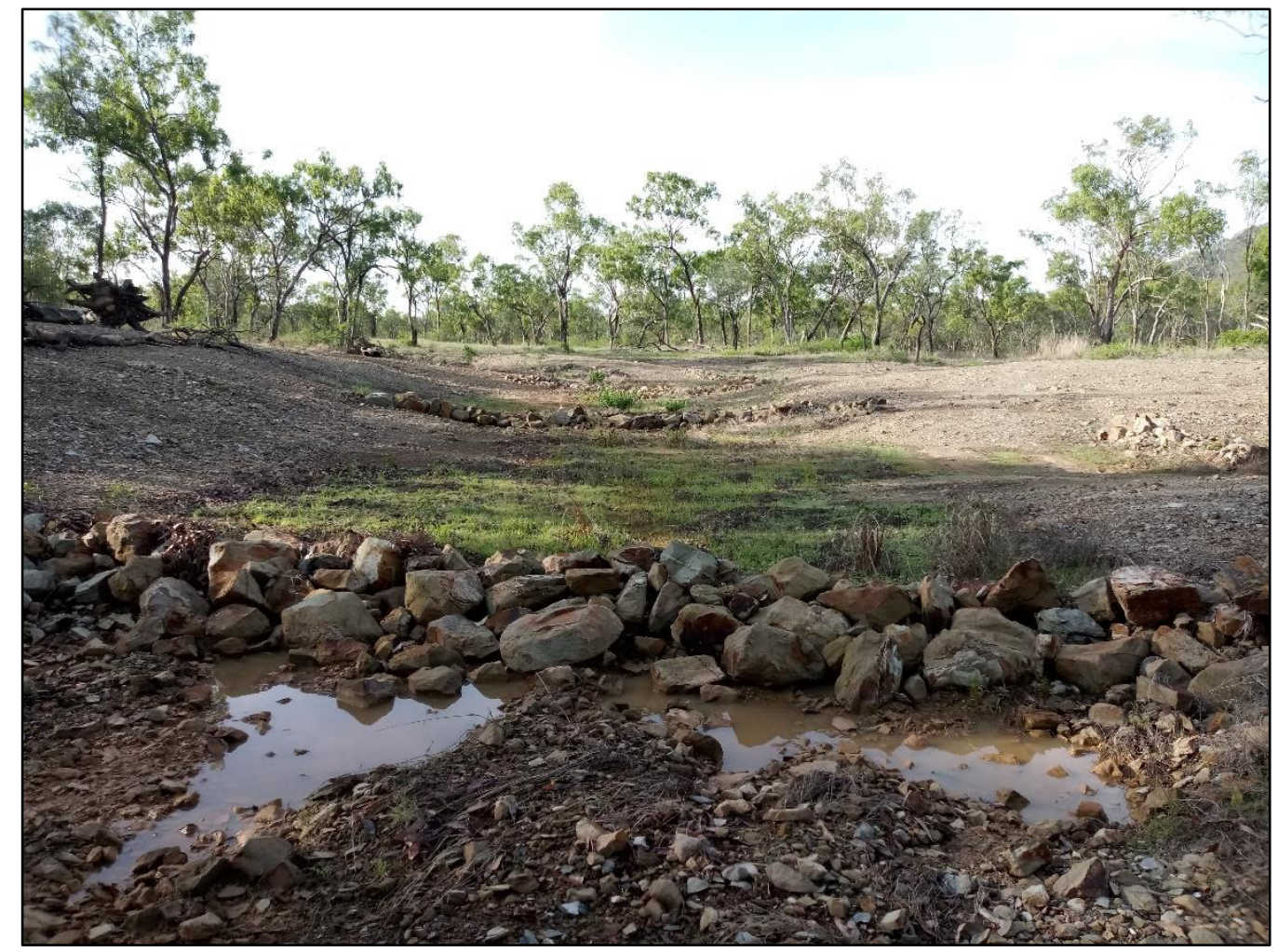

Figure S9C. Looking upstream into remediated gully at same location as Figure SI-9B. Photo taken in on 16/02/2018. Note the check dam has collected coarse sediment and now supports vegetation. 
Table S10A. Pearson's correlation analysis of SSC and nutrient fractions of samples collected from the control gully on 24/01/2018.

\begin{tabular}{|c|c|c|c|c|c|c|c|}
\hline \multicolumn{8}{|c|}{ Control Gully } \\
\hline Analytes compared & $\boldsymbol{r}$ & $\begin{array}{c}95 \% \text { confidence } \\
\text { interval }\end{array}$ & $\begin{array}{c}R \\
\text { squared }\end{array}$ & $\begin{array}{c}P \\
\text { (two-tailed) }\end{array}$ & $\begin{array}{c}\text { P value } \\
\text { summary }\end{array}$ & $\begin{array}{c}\text { Significant? } \\
(\text { alpha }=0.05)\end{array}$ & $\begin{array}{c}\text { Number of } \\
\text { XY Pairs }\end{array}$ \\
\hline SSC vs.Dissolved OC & -0.2228 & -0.5890 to 0.2195 & 0.04962 & 0.3191 & ns & No & 22 \\
\hline SSC vs.POC & 0.6951 & 0.3868 to 0.8636 & 0.4831 & 0.0003 & $* * *$ & Yes & 22 \\
\hline SSC vs. Total $\mathrm{N}$ as $\mathrm{N}$ & 0.7675 & 0.5113 to 0.8984 & 0.589 & $<0.0001$ & $* * * *$ & Yes & 22 \\
\hline SSC vs. Total nitrogen (dissolved) as $\mathrm{N}$ & -0.3307 & -0.6603 to 0.1056 & 0.1094 & 0.1327 & ns & No & 22 \\
\hline SSC vs. Total N (suspended) as N & 0.7759 & 0.5266 to 0.9024 & 0.6021 & $<0.0001$ & $* * * *$ & Yes & 22 \\
\hline$\underline{\mathrm{SSC}}$ vs.Ammonium $\mathrm{N}$ as $\mathrm{N}$ & -0.1665 & -0.5496 to 0.2743 & 0.02774 & 0.4588 & ns & No & 22 \\
\hline SSC vs.Oxidised nitrogen as $\mathrm{N}$ & -0.6403 & -0.8399 to -0.2883 & 0.41 & 0.0018 & $* *$ & Yes & 21 \\
\hline$\underline{\text { SSC vs. Total Kjeldahl } \mathrm{N} \text { as } \mathrm{N}}$ & 0.7708 & 0.5173 to 0.8999 & 0.5941 & $<0.0001$ & $* * * *$ & Yes & 22 \\
\hline SSC vs.Phosphate $\mathrm{P}$ as $\mathrm{P}$ & -0.4957 & -0.7639 to -0.08144 & 0.2457 & 0.0223 & $*$ & Yes & 21 \\
\hline$\underline{\text { SSC vs. Total Kjeldahl } \mathrm{P} \text { as } \mathrm{P}}$ & 0.6609 & 0.3317 to 0.8466 & 0.4367 & 0.0008 & $* * *$ & Yes & 22 \\
\hline SSC vs.Dissolved Kjeldahl P as P & -0.3086 & -0.6462 to 0.1299 & 0.09525 & 0.1623 & ns & No & 22 \\
\hline
\end{tabular}

$P=$ phosphorus, $N=$ Nitrogen, $P O C=$ particulate organic carbon . 
Table S10B. Pearson's correlation analysis of SSC and nutrient fractions of samples collected from the remediated gully on 24/01/2018.

\begin{tabular}{|c|c|c|c|c|c|c|c|}
\hline \multicolumn{8}{|c|}{ Remediated Gully } \\
\hline Analytes compared & $\boldsymbol{r}$ & $\begin{array}{c}95 \% \text { confidence } \\
\text { interval }\end{array}$ & $\begin{array}{c}R \\
\text { squared }\end{array}$ & $\begin{array}{c}P \\
\text { (two-tailed) }\end{array}$ & $\begin{array}{l}\text { P value } \\
\text { summary }\end{array}$ & $\begin{array}{l}\text { Significant? } \\
(\text { alpha }=0.05)\end{array}$ & $\begin{array}{c}\text { Number of } \\
\text { XY Pairs }\end{array}$ \\
\hline SSC vs.Total OC & 0.2898 & -0.4636 to 0.7999 & 0.08397 & 0.4494 & ns & No & 9 \\
\hline SSC vs.Dissolved OC & 0.19 & -0.5426 to 0.7584 & 0.03608 & 0.6245 & ns & No & 9 \\
\hline SSC vs.POC & 0.2312 & -0.5114 to 0.7762 & 0.05347 & 0.5494 & ns & No & 9 \\
\hline SSC vs.Total $\mathrm{N}$ as $\mathrm{N}$ & 0.4464 & -0.3095 to 0.8566 & 0.1993 & 0.2284 & ns & No & 9 \\
\hline SSC vs.Organic N (dissolved) as $\mathrm{N}$ & 0.655 & -0.01613 to 0.9193 & 0.429 & 0.0555 & ns & No & 9 \\
\hline SSC vs.Total nitrogen (dissolved) as $\mathrm{N}$ & 0.8752 & 0.5040 to 0.9735 & 0.766 & 0.002 & $* *$ & Yes & 9 \\
\hline SSC vs.Total N (suspended) as N & 0.2812 & -0.4708 to 0.7966 & 0.07909 & 0.4635 & ns & No & 9 \\
\hline SSC vs.Ammonium $\mathrm{N}$ as $\mathrm{N}$ & -0.1544 & -0.7424 to 0.5680 & 0.02383 & 0.6917 & ns & No & 9 \\
\hline SSC vs.Oxidised nitrogen as $\mathrm{N}$ & 0.7484 & 0.1676 to 0.9436 & 0.5601 & 0.0204 & $*$ & Yes & 9 \\
\hline SSC vs.Total Kjeldahl $\mathrm{N}$ as $\mathrm{N}$ & 0.3899 & -0.3701 to 0.8372 & 0.152 & 0.2996 & ns & No & 9 \\
\hline SSC vs.Dissolved Kjeldahl $\mathrm{N}$ as $\mathrm{N}$ & 0.657 & -0.01269 to 0.9198 & 0.4316 & 0.0545 & ns & No & 9 \\
\hline SSC vs. Total P (suspended) as P & 0.4864 & -0.2626 to 0.8696 & 0.2365 & 0.1843 & ns & No & 9 \\
\hline SSC vs.Organic $\mathrm{P}$ (dissolved) as $\mathrm{P}$ & 0.00184 & -0.6631 to 0.6651 & $3.4 \mathrm{E}-06$ & 0.9962 & ns & No & 9 \\
\hline SSC vs.Phosphate $\mathrm{P}$ as $\mathrm{P}$ & $<\mathrm{LOD}$ & $<\mathrm{LOD}$ & $<\mathrm{LOD}$ & $<\mathrm{LOD}$ & $<\mathrm{LOD}$ & No & 9 \\
\hline SSC vs.Total Kjeldahl $\mathrm{P}$ as $\mathrm{P}$ & 0.5362 & -0.1987 to 0.8851 & 0.2875 & 0.1367 & ns & No & 9 \\
\hline SSC vs.Dissolved Kjeldahl $\mathrm{P}$ as $\mathrm{P}$ & -0.1127 & -0.7227 to 0.5960 & 0.01271 & 0.7727 & ns & No & 9 \\
\hline
\end{tabular}

$P=$ phosphorus, $N=$ Nitrogen, $P O C=$ particulate organic carbon. 

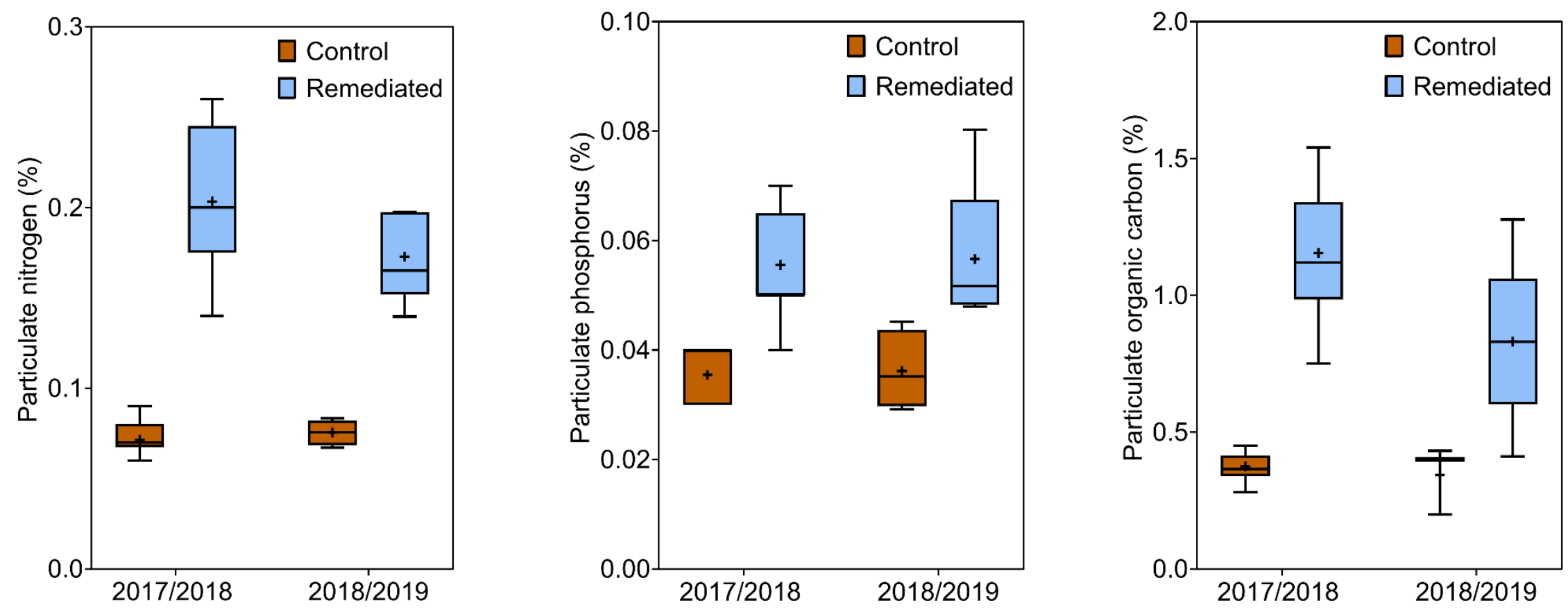

S11. Nutrient concentration of suspended sediment presented as a percentage of SSC for samples collected during flow events in the remediated (blue) and control (brown) gullies events in the 2017/2018 and 2018/2019 wet seasons. Note, the 2017/2018 data represents a single flow event and the 2018/2019 data represent multiple flow events. Nutrient content represents the mass of particulate nutrients as a component of the total suspended sediment mass, expressed as a percentage. 